\title{
NOTAS SOBRE UM ARQUIVO: ALEXANDRE EULALIO E ALVIM CORRÊA
}

\author{
Flávia Carneiro Leão
}

Doado ao Centro de Documentação Cultural "Alexandre Eulalio", CEDAE, logo após seu falecimento, o espólio de Alexandre Eulalio Pimenta da Cunha (1932-1988) documenta sua atividade intelectual e atuação como crítico de arte, de literatura e historiador entusiasmado pela história e cultura brasileiras.

Composto por 8.0oo documentos e por uma biblioteca com 14.000 volumes ${ }^{1}$, o fundo documental de Alexandre Eulalio evidencia a multiplicidade de interesses de pesquisa de seu titular, sendo constituído por conjuntos documentais com temáticas variadas, que vão de Machado de Assis a Gonzaga Duque, de Cornelio Penna a Lúcio de Mendonça, de Jorge de Lima a Aureliano Lessa, passando pelo Império Brasileiro ou, ainda, Diamantina, "sua cidade" de adoção.

Henrique Alvim Corrêa nasceu no Rio de Janeiro, em 30 de janeiro de 1876 e, em 1892, transferiu-se com Alvim Corrêa. Reprodu-

1 Os volumes da biblioteca de Alexandre Eulalio encontram-se preservados na Biblioteca Central Cesar Lattes - Coleções Especiais e Obras Raras, BC-CEOR, e os documentos no Centro de Documentação Cultural “Alexandre Eulalio”, CEDAE, do Instituto de Estudos da Linguagem. Dentre esses conjuntos, destaca-se o núcleo de documentos de/sobre o artista, pintor, gravurista e ilustrador, Alvim Corrêa. 
a família para a Europa, onde viveu, sucessivamente, em Lisboa, Paris e Bruxelas. Em Paris estudou com um dos mais populares pintores da escola francesa do século XIX, Edouard Détaille. Em Bruxelas, casou-se, trabalhou, expôs, tendo falecido, ainda jovem, em 1910.

Interessado pela obra de Alvim Corrêa e, sobretudo, pelo século XIX brasileiro, Alexandre Eulalio reuniu em seu arquivo, tanto reproduções de documentos como originais. Dentre as reproduções apontamos as de desenhos, gravuras, fotografias e caricaturas, de recortes de periódicos da época, como "La Gazerre", "Journal de Bruxelles", "La Chronique”... que trazem críticas e comentários sobre exposições do pintor.

Quanto aos originais que integram o conjunto, além de catálogos e cronologias da vida e obra de Cartaz de divulgacăo da edição Alvim Corrêa, destacam-se quatro ilustrações da série por Alvim Corrêa. Reprodução publicada na edição belga de 1906 de A Guerra dos Mundos, de H. G. Wells.

A série criada por Alvim Corrêa é composta por 32 desenhos e 100 ilustrações que recriam, por assim dizer, a obra de Wells segundo seu próprio gênio e inspiração. Os desenhos do conjunto, cujo destino parece ter sido a venda no exterior, possuem um encadeamento independente da sequência narrativa do romance, ao passo que as ilustrações têm uma correlação direta com a sequência e o desenrolar da trama, transpondo para o papel, através do traço, cenas e episódios do texto de Wells.

Neste sentido, um exemplo pode ser verificado em uma das quatro ilustrações conservadas no CEDAE e empregada na página cujo texto descreve uma jogatina entre dois personagens que, "às portas da extinção, -ou da mais aterradora degradação que imaginar se possa; [...] sem outra perspectiva à vista da morte, e morte horrível" ali estavam, "com toda a calma do mundo a fumar charutos e beber vinho, como se nada mais importasse senão o destino daqueles cartões ou a sorte do coringa."

As demais ilustrações presentes noacervo sofrem emprego semelhante na edição de 1906, ou seja, são publicadas à margem das páginas, como representações plásticas Ilustração de Alvim Corrêa para a $2^{\mathrm{a}}$ edição de $A$ Guerra dos Mundos por L. dotextoqueacompanham.

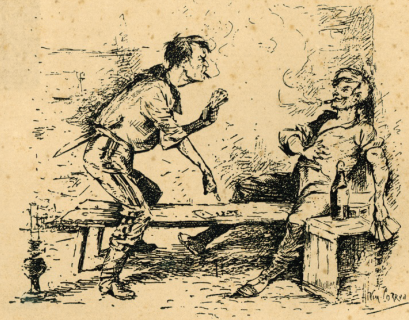

Vandamme. Bico de pena, 12, 2 × $26 \mathrm{~cm}$. 

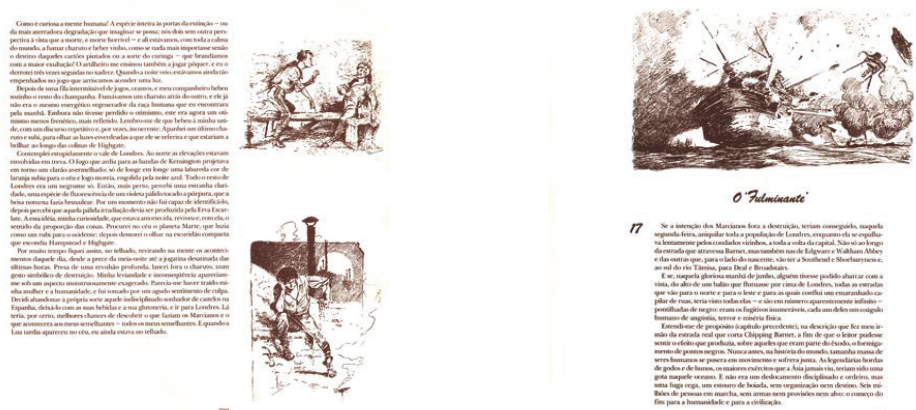

Páginas da edição de $A$ Guerra dos Mundos, publicada pela Editora Nova Fronteira, no Rio de Janeiro em 1981.

Fundo Alexandre Eulalio, BC/CEOR

Ainda hoje pouco conhecidos, o nome e a obra de Alvim Corrêa começaram a ser apreciados e valorizados com as exposições e publicações que se fizeram a partir de 1965, no Brasil, quando José Roberto Teixeira Leite publicou A gravura brasileira contemporânea, livro em que reconhece que "Essa obra gráfica é valiosa por dois motivos: por sua qualidade intrínseca e pelo momento histórico em que foi realizada, antes até de que, em Florença, Carlos Oswald efetuasse as primeiras chapas".

Em 1972, Pietro Maria Bardi organizou a primeira exposição de sua obra no Museu de Arte de São Paulo, MASP. Um ano após, uma nova exposição, desta vez no Museu de Arte Moderna do Rio de Janeiro, apresentou uma admirável seleção de desenhos e telas do artista.

Desta maneira se deram, portanto, as primeiras divulgações da obra de Alvim Corrêa que, mesmo sendo pouco difundida, continuou sendo alvo de Ilustração de Alvim Corrêa para a $2^{a}$ edição de $A$ Guerra dos Mundos por exposições posteriores como

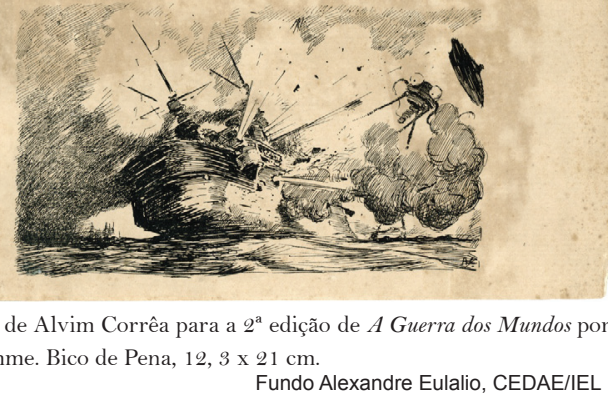
as ocorridas em 1977 e 1990, no Museu Nacional de Belas Artes, e em 1981, na Fundação Casa de Rui Barbosa, no Rio de Janeiro, esta última organizada por Alexandre Eulalio e motivadora do ensaio "Henrique Alvim Corrêa: Guerra E Paz. Cotidiano e imaginário de um pintor brasileiro no 1900 europeu", publicado neste volume.

Com relação ao reconhecimento dos trabalhos de Alexandre Eulalio acerca de Alvim Corrêa, vale citar a dedicatória encontrada à folha de rosto do exemplar de A Guerra dos Mundos que pertenceu a Alexandre Eulalio:

"Alexandre: ninguém merece mais este livro do que você por teres escrito o mais lúcido, profundo e documentado trabalho até hoje feito 
194 - Remate de Males 32.2

sobre a vida e obra de Alvim Corrêa! A você Alexandre, companheiro de bem longínquas jornadas universitárias, ofereço com franco apreço $e$ muita admiração. ${ }^{2}$

Sergio [Alvim Corrêa]. Rio [de Janeiro], 19/7/1984".

\section{REFERÊNCIAS BIBLIOGRÁFICAS}

BARROS, Maria Stella Teixeira de. Henrique Alvim Corrêa: correspondências e afinidades. São Paulo, Dissertação (mestrado) - Faculdade de Filosofia, Letras e Ciências Humanas - Universidade de São Paulo, São Paulo, FFLCH/USP, 1996.

EULALIO, Alexandre. Henrique Alvim Corrêa: guerra e paz. Cotidiano e imaginário na obra de um pintor brasileiro no 1900 europeu. Rio de Janeiro: Fundação Casa de Rui Barbosa, 1981.

GAlERIA ARTE GLOBAL, São Paulo. Alvim Corrêa. Óleos e desenhos. Apres. de Pietro Maria Bardi. São Paulo, 1983. il. (Catálogo de Exposição).

LEITE, José Roberto Teixeira. A gravura brasileira contemporânea. Rio de Janeiro: Rio, 1965.

MUSEU DE ARTE MODERNA, Rio de Janeiro. Alvim Corrêa. Pinturas e desenhos. Apres. de R. A. C. Texto de José Roberto Teixeira Leite. Rio de Janeiro, (Catálogo de Exposição), 1973.

MUSEU NACIONAL DE BELAS ARTES, Rio de Janeiro. Henrique Alvim Corrêa. Cenas da vida militar. Apres. de Alcídio Mafra de Souza. Texto de Pedro Xexéo. Rio de Janeiro, (Catálogo de Exposição) ,1990.

WELLS, H. G. A Guerra dos Mundos. Trad. Raul de Sá Barbosa. Rio de Janeiro; Nova Fronteira, 1981.

2 Transcrição da dedicatória que se encontra à folha de rosto do exemplar que pertenceu à Alexandre Eulalio de A Guerra dos Mundos, publicado pela Editora Nova Fronteira, no Rio de Janeiro em 1981. 